\title{
TRABALHO E TERCEIRIZAÇÃO: IMPLICAÇÕES NAS POLÍTICAS DE EDUCAÇÃO E TRABALHO PARA JOVENS NO BRASIL
}

\author{
Yossonale Viana Alves*, Márcio Adriano Azevedo \\ *E-mail: sonalealves@hotmail.com \\ Instituto Federal de Educação, Ciência e Tecnologia do Rio Grande do Norte, Brasil \\ DOI: $10.15628 /$ rbept.2020.6953 \\ Artigo submetido em fev/2018 e aceito em jan/2020
}

\section{RESUMO}

O artigo analisa as mudanças no mundo do trabalho diante da atual crise econômica brasileira, em especial, o advento da terceirização e de seus efeitos nas políticas de educação e trabalho para jovens brasileiros. Para tal fim, utilizou-se a metodologia de observação contextualizada, análise de instrumentos e dispositivos legais, pesquisa bibliográfica em autores que discutem o mundo do trabalho, a terceirização, e a educação e o trabalho para jovens dentro de uma visão histórico-crítica como atividades humanas. Concluiu-se que, na última década, há uma tendência de empobrecimento das classes trabalhadoras em virtude do avanço da flexibilização de uma série de leis trabalhistas, resultando no aprofundamento da degradação das condições de vida e de trabalho.

Palavras-chave: Terceirização. Trabalho e Educação. Políticas. Juventudes.

\section{WORK AND THIRD PARTICIPATION: IMPLICATIONS ON EDUCATION AND WORK POLICIES FOR YOUNG PEOPLE IN BRAZIL}

\begin{abstract}
The article analyzes the changes in the world of work in the face of the current Brazilian economic crisis, especially the advent of outsourcing and its effects on education and work policies for Brazilian youth. To that end, the methodology of contextualized observation, analysis of instruments and legal devices, bibliographic research in authors that discuss the world of work, outsourcing, education and work for young people within a historical-critical view as activities human beings. It has been concluded that in the last decade there has been a trend towards the impoverishment of the working classes as a result of the increase in the flexibility of a series of labor laws, resulting in a deepening of the deterioration of living and working conditions.
\end{abstract}

Keywords: Outsourcing. Work and Education. Policies. Youth. 


\section{INTRODUÇÃo}

O ambiente do trabalho vive, na atualidade, os efeitos de uma crise capitalista com novas particularidades (entrelaçamento entre os fatores produtivos, econômicos e sociais), de forma a alcançar o capital financeiro que se desenvolveu a partir do centro em direção à periferia da economia mundial. Esse atributo, entretanto, não torna menos perversos os seus reflexos sobre todo o mundo, pois apesar do impacto sobre as economias centrais ter sido mais intenso num primeiro momento, os efeitos da crise chegaram às economias periféricas, que, em geral, têm estruturas socioeconômicas mais sensíveis e permeáveis às investidas capitalistas.

Os efeitos nefastos da crise do capital em meio a tanta destruição de forças produtivas, da natureza e do meio ambiente, promovem também, em escala global, uma ação destrutiva e deletéria contra a força humana de trabalho, refletindo-se em enormes contingentes precarizados ou mesmo à margem do processo produtivo, elevando, de igual maneira a intensidade dos níveis de desemprego estrutural. (ANTUNES, 2005).

O trabalho, como um dos fatores essenciais do sistema econômico, padece dos males do contexto e, do mesmo modo, reflete a crise do capital, e a força de trabalho, como de outras vezes, está entre as primeiras vítimas com o encerramento das chances de emprego que, de início, ocorreu nas instituições financeiras como um todo, vitimando, em seguida, a indústria, o comércio, a agricultura e os demais segmentos dos setores de serviços.

A principal característica do novo complexo de reestruturação produtiva que abrolha sob a era neoliberal, é o seu caráter irruptivo sobre o trabalho, constituindo-se, a partir disso, um novo e precário mundo do trabalho no Brasil, ou seja, implementa-se um novo estigma ao mundo do trabalho: o desemprego estrutural, a precariedade de emprego e de salário, além da parcela imensa de "marginalizados" com relação à legislação trabalhista. (ALVES, 2007).

Assim, como produto da reestruturação produtiva do capital e face à necessidade de elevação da produtividade, vai-se impondo a consequente reorganização do mercado de trabalho. Esta, ascendeu configurada pela nova ordem neoliberal globalizante, a "terceirização", que, no país, caracteriza-se por todo processo de contratação de trabalhadores por empresas interpostas.

Nesse âmbito, o que as políticas de educação e trabalho, acopladas à terceirização e analisadas à luz de uma concepção histórico-dialética sobre as atividades humanas significam para jovens inseridos no mundo do trabalho? Quais as condições de trabalho e as perspectivas educacionais para as juventudes frente às atuais políticas direcionadas à terceirização? 
Percebemos que, de um modo geral, há uma tendência de não incentivo à educação na vida do ser humano. A crise na educação envolve muitos aspectos, sejam de gestão, políticos, estruturais, orçamentários, entre outros. Apesar disso, somos sempre tentados a acreditar que estamos perante a problemas específicos, delimitados pela história e pelas fronteiras nacionais, os quais só dizem respeito a quem por eles é diretamente atingido. Essa perspectiva é parte de um processo alienante e prejudicial à visão de educação como formação humana emancipatória.

A educação e o trabalho são direitos constitucionais indissociáveis e, a crise na educação, recai também como um problema para o mundo do trabalho. Ora, a contínua desvalorização do trabalho, imposta por políticas de cunho neoliberal, faz crescer a preocupação com o aumento do desemprego e da pobreza, bem como com o achatamento salarial, tendo em vista que as condições de trabalho se deterioraram com o incremento da carga horária laboral, com a submissão a atividades exaustivas, com o crescimento do trabalho eventual e informal, entre outras precariedades que pouco têm a ver com a educação.

É nesse viés, caracterizado por um processo de precarização estrutural da educação e do trabalho, que se promove um verdadeiro desmonte da legislação social protetora da garantia de acesso à educação e ao trabalho. Então, flexibilizar a legislação social de ambos os direitos significa aumentar, ainda mais, os mecanismos de extração do trabalho e a ampliação das formas de precarização e destituição dos direitos sociais que foram árdua e historicamente conquistados.

É a partir da nova crise do capital, sob o impulso das políticas neoliberais e do complexo de reestruturação produtiva, que a classe operária industrial declinou nos principais países capitalistas. Desde meados dos anos 1970, vem ocorrendo uma nova divisão internacional do trabalho, conduzindo a classe trabalhadora a uma outra composição do proletariado nos principais países capitalistas desenvolvidos. Isso vai acirrar algumas tendências estruturais que apontavam para a diminuição da classe operária industrial.

A constituição de um novo e precarizado mundo do trabalho, sob a mundialização do capital, contribuiu para a debilitação estrutural do poder sindical e político da classe dos trabalhadores assalariados. Vemos, também, que o cerne determinante da crise do sindicalismo moderno é a instauração do complexo modelo de reestruturação produtiva, que é capaz de impulsionar e desenvolver o novo e precarizado mundo do trabalho ao qual já nos referimos.

Clarividente que as classes trabalhadoras vêm sofrendo profundas mudanças, tendo em vista que a força humana disponível para o trabalho, hoje, ou já se encontra exercendo trabalhos parciais, precários, efêmeros, temporários, desumanos, cruéis, ou já se vivencia o desemprego. Esse cenário de falta de educação e trabalho, de insegurança, de desigualdade, de 
inadequada remuneração e de falta de liberdade, são características atuais do mundo do trabalho.

Um dos grupos mais prejudicados com as mudanças no mundo do trabalho é o das juventudes. Muitos jovens acabam por ingressar no mundo do trabalho prematuramente, para colaborar com o suprimento das necessidades familiares. Outros, para conquistarem seu espaço, sua independência, sua autonomia e, de certa forma, um pouco de liberdade.

A participação do adolescente no mercado de trabalho tem provocado muitos questionamentos, dificultando e interferindo na implementação de políticas específicas voltadas para o trabalho do jovem, pois, no atual momento, alcançam a idade de ingresso no mercado de trabalho sem perspectiva alguma de emprego, fato que coopera para endossar as fileiras dos trabalhos precários, terceirizados e dos índices de desempregados ou desocupados.

É, portanto, a partir de tal realidade mundializada e diferenciada, que pretendemos discutir a crise no mundo do trabalho e a terceirização, destacando suas modalidades, suas especificidades e suas convergências e identidades, bem como seus reflexos para os jovens.

\section{MUNDO DO TRABALHO E AS REGULAÇÕES REGRESSIVAS DAS RELAÇÕES TRABALHISTAS}

Um conjunto de medidas estruturais foi adotado com o objetivo de criar um ambiente institucional favorável para o capital produtivo, assegurando a possibilidade de reduzir custos por meio da Reforma Trabalhista (Lei n. ${ }^{\circ}$ 13.467, de 13 de julho de 2017) e da ampliação da terceirização (Lei n. ${ }^{\circ} 13$. 429, de 31 de março de 2017).

As transformações do trabalho nas últimas décadas podem ser traduzidas nos processos de flexibilização e de precarização que marcam esse período em todo o mundo. Ao examinarmos a literatura constituída pelos estudos no Brasil (ANTUNES, 2005; FRIGOTTO, 2004; GIOVANNI, 2007; KUENZER, 2008), notamos que uma das dimensões mais pesquisadas da flexibilização são as ditas "novas formas de gestão e de organização do trabalho", inspiradas no Toyotismo, que tem na terceirização, uma de suas principais práticas.

Ao longo da história, a relação dialética entre trabalho e educação foi afetada pelas diferentes formas de gestão da produção capitalista, bem como pelo Estado que se organizou sobre cada nova base material. De início, no período da indústria taylorista, criou-se uma forma de administração que mirava simplificar e controlar o trabalho em suas minúcias, retirando do trabalhador toda a liberdade criativa. 
Em seguida, ocorre a simplificação e a intensificação extremada do trabalho, agora por meio da linha de produção fordista, de um ritmo de trabalho determinado pela velocidade das máquinas e do oferecimento de "altos salários" passíveis de estimular o consumo de bens pelos próprios operários. Ao mesmo tempo que a indústria fordista se expandia, surgiam os primeiros Estados de Bem-Estar Social modernos, organizados para garantir uma série de direitos sociais à população, como saúde, educação e garantias trabalhistas.

Nos anos 1960 e 1970, porém, sobreveio uma grave crise econômica e política que esbarrou na própria lógica expansiva, destrutiva e incontrolável do capital globalizante. Em resposta a essa crise generalizada, veio a ofensiva do capital e do Estado: o neoliberalismo, que mitigou as garantias do Estado Social e perseguiu as organizações operárias; e o Toyotismo, pela generalização de um novo padrão produtivo.

O novo modelo de gestão trazia a aplicação de técnicas administrativas e de tecnologias que permitiam a flexibilização da produção e a alteração das relações empregado e empresa. A nova correlação de forças demandou um olhar liberal sobre a educação, revelado na Teoria do Capital Humano, isto é, mediante a predominância de uma visão tecnicista, passouse a disseminar a ideia de que a educação é o pressuposto do desenvolvimento econômico, bem como do desenvolvimento do indivíduo, que, ao educar-se, estaria "valorizando" a si próprio, na mesma lógica em que se valoriza o capital.

É a partir da mundialização do capital que se desenvolve um complexo de restruturação produtiva, com impactos estruturais no mundo do trabalho. Surge como ofensiva do capital na produção, tendo em vista que debilita a classe, não apenas no aspecto objetivo, com a constituição de um precário mundo do trabalho, mas, sobretudo, no subjetivo.

Nas últimas décadas do Século XX, uma nova conjuntura histórica se ergue num quadro de crise do capitalismo e, nesse contexto, a flexibilização e a precarização do trabalho se transformam, assumindo novas dimensões e configurações.

Seguindo esse período de avanços e de transformações, o trabalhador foi ficando em segundo plano, visto que as máquinas, muitas vezes, substituíram sua força de trabalho. Assim, o campo de trabalho reduziu-se para dar espaço à produção mecânica.

Uma das características histórico-ontológicas da produção capitalista é a de sempre "flexibilizar" as condições de produção, principalmente, a força de trabalho. Na visão marxista, um dos traços ontológicos do capital é a sua notável capacidade em "desmanchar tudo o que é sólido" e revolucionar de modo constante as condições de produção; pôr - e repor - novos patamares de mobilidade do processo de valorização dos novos segmentos da classe 
dos trabalhadores assalariados em seus vários aspectos. (MARX, 1990, apud ALVES, 2000, p. 22).

Nesse processo transformativo, nefasto e perverso, inúmeros trabalhadores vivem a insegurança diária dos seus empregos, que se tornam obsoletos para as qualificações exigidas nesse novo e precário mundo do trabalho, transfigurando-se em grupos de reserva, grupos desqualificados dentro dos novos padrões mercadológicos. Esses trabalhadores vão configurar a classe de trabalhadores informais, que, retirados do mercado de trabalho, irão se reagrupar em outras condições, em outros padrões para continuarem sendo oprimidos e explorados.

O mundo do trabalho, sob o novo complexo de reestruturação produtiva, é permeado não apenas por novos tipos de controle do trabalho, mas, sobretudo, por uma nova exclusão social, caracterizada pelo desemprego estrutural que atinge os polos industriais mais desenvolvidos (ALVES, 2005). A atual tendência dos mercados de trabalho é a de reduzir o número de trabalhadores "centrais" e empregar cada vez mais uma força de trabalho que entra facilmente e é demitida sem custos quando as coisas ficam ruins. (HARVEY, 1993).

Assim, a consequente reorganização do mercado de trabalho fez rebelar a "terceirização". Seu conceito é datado na Segunda Guerra Mundial, momento no qual as empresas precisavam concentrar-se na produção de armamentos de modo a atender a demanda existente. Com esse intuito, passaram a focar na atividade principal e delegaram as atividades secundárias a empresas prestadoras de serviço, como parte da suposta melhoria do processo e da técnica de gestão administrativa e operacional das empresas. (PETRIN, 2016).

No cenário mundial, a terceirização assume características semelhantes nos diversos países que a utilizam e, em cada um, ela se estrutura de uma maneira dependente dos fatores estruturais, históricos, culturais, econômicos, políticos, dentre outros. No âmbito brasileiro, a terceirização se intensificou a partir da década de 1990, atingindo não somente as áreas periféricas, como também as centrais. De início, a prática era conhecida como a contratação de serviços de terceiros, principalmente de mão de obra, com o intuito de reduzí-la em seus custos com o claro objetivo terceirizar e ter ganhos de qualidade, de eficiência, de especialização, de eficácia e de produtividade da atividade principal da empresa, e os itens acessórios ficariam por conta da empresa terceirizada.

Podemos dizer que, para os defensores da terceirização, as cridas vantagens são as de: redução das despesas e a racionalização de atividades e de processos; contratação de serviços de terceiros como elevação do grau de execução das atividades; redução dos custos de mão de obra; redução do quadro de funcionários e de níveis hierárquicos; potencialização da competitividade entre empresas; garantia de ganhos com a especialização, 
qualificação, eficiência, produtividade e competitividade para e entre as empresas.

E as desvantagens: a contratação da terceirização para atividades de finalização pode levar à perda de aptidões e de conhecimentos básicos do trabalhador, que não sabe o que está produzindo; a falta de credibilidade por parte dos contratantes com empresas terceirizadas; contratos vagos e confusos; problemas de comunicação dentro da organização; falta de controle sobre as atividades terceirizadas; cobrança excessiva por parte do contratante que visa à redução de custo; aumento da rotatividade de mão de obra e dos níveis de desemprego.

A terceirização, em sua face mais perversa, conduz à redução de custos pela via da exploração de trabalho em condições e relações precárias, em detrimento da lei e da influência sindical, sem mencionar que estimula a rotatividade de mão de obra, uma vez que os trabalhadores terceirizados são, comumente, menos especializados e facilmente substituíveis. Convém acrescentar, ainda, que esse processo de terceirização desorganiza perversamente a atuação sindical e, praticamente, suprime qualquer possibilidade eficaz de ação, de atuação e de representação coletivas dos trabalhadores terceirizados.

A falta de regulamentação legislativa propiciou o aumento das terceirizações, já que o setor privado sopesou que, não havendo impedimento, a terceirização poderia acontecer livremente, o que motivou o surgimento de empresas cuja única atividade era a de fornecimento de mão de obra para outras empresas. O empresariado, frise-se, não tinha objetivo de ofertar bens ou serviços, e sim a força de trabalho, rebaixada à condição de mercadoria.

Adite-se, a esse raciocínio, que a terceirização teve impulso na década de 1980 como incentivo à reestruturação produtiva, à privatização de empresas públicas e à desregulamentação das relações de trabalho. 0 processo foi intensificado e disseminado no âmbito da reestruturação produtiva que elevou o padrão de qualidade com a redução do tempo e do aumento da flexibilidade dos sistemas produtivos de bens e de serviços, com o objetivo de diminuir os custos da produção. Porém, o que observamos, na prática, na maioria dos casos, é um convite à precarização das condições de trabalho e um acinte aos valores humanitários do trabalho.

Diante desse panorama, e buscando controlar os efeitos negativos trazidos pela onda de terceirizações, o Tribunal Superior do Trabalho (TST) promulgou a Súmula $\mathbf{n} .^{\circ} 331$, contemplando as hipóteses de ilegalidade e de legalidade da terceirização no ordenamento jurídico brasileiro. Contudo, apesar desse avanço, o fenômeno da terceirização continua ganhando espaço, especialmente em sua versão precarizante face às políticas de cunho neoliberais existentes. (BRASIL, 2011). 
Para mais, em 31 de março de 2017, foi sancionada a Lei da Terceirização pelo Presidente Michel Temer. O objetivo foi o de atender aos anseios empresariais, usando-se, para isso, o momento de crise econômica que vive o Brasil, fato que representa uma violação ao Direito do Trabalho, porque a lei veio para reconhecer a possibilidade de terceirização ampla e irrestrita, mas sem garantias reais e compensatórias para os trabalhadores terceirizados.

A nova Lei colide com os compromissos de proteção à cidadania, à dignidade da pessoa humana e aos valores sociais do trabalho previstos no Art. 1ํ da Constituição Federal, que, também em seu Art. 3ํㅡ, estabelece como objetivos fundamentais da República: "construir uma sociedade livre, justa e solidária, bem como erradicar a pobreza, a marginalização e reduzir as desigualdades sociais e regionais". (BRASIL, 1988).

O que se vê na prática efetiva, por exemplo, são as seguintes desvantagens para os trabalhadores terceirizados: a) salários, benefícios e condições de trabalho inferiores aos recebidos pelos empregados diretamente contratados pela tomadora de serviços; b) precarização das condições de trabalho, evidenciadas por ambientes laborativos inseguros e inadequados que provocam muitos acidentes de trabalho; c) desorganização sindical; d) agencia a desmobilização dos trabalhadores sobre reivindicações trabalhistas; e) gera a desmobilização dos trabalhadores sobre a realização de greves e elimina as ações sindicais.

Indubitavelmente, a terceirização acarretará, para milhões de trabalhadores no Brasil, o rebaixamento de salários e de suas condições de trabalho, instituindo, como regra, a precarização nas relações laborais, sem mencionar a elevada taxa de rotatividade que acometerá os profissionais terceirizados.

As recentes reviravoltas ocorrentes no mundo do trabalho atravessam a vida da população, produzindo formas específicas de vínculos que não têm correspondido a uma ampliação do acesso à dignidade humana por intermédio do direito ao trabalho e à renda. Todos os segmentos, inclusive o de jovens, sofrem tais efeitos, e mesmo respeitadas suas particularidades, a problemática atual do trabalho não é atenuada, e sim incrementada.

É público e notório que a terceirização, de um modo geral, tem causado a degradação das relações de trabalho, com redução significativa dos direitos dos trabalhadores e da qualidade do emprego. A estratégia de otimização dos lucros mediante a terceirização está fortemente baseada na precarização do trabalho.

Dentre seus principais efeitos danosos para os trabalhadores brasileiros encontram-se o descaso com as condições de saúde e de segurança no trabalho, a redução de direitos, a exigência de jornadas excessivas ou superiores aos limites legais, a maior rotatividade no emprego, a dispersão e a falta da representatividade sindical. 
Os acidentes e as mortes no trabalho são a faceta mais terrível da terceirização no país. Dados estatísticos da Fundação Comitê de Gestão Empresarial (COGE) comprovam que os trabalhadores terceirizados estão muitos mais sujeitos a infortúnios no local de trabalho do que os trabalhadores contratados diretamente. Esses fatos impactam profundamente nos cofres do Sistema Único de Saúde (SUS) e da Previdência Social, gerando gastos com atendimentos hospitalares e com pagamento de benefícios previdenciários, impactando negativamente todo o sistema de Seguridade Social.

Não bastassem esses efeitos maléficos para os trabalhadores, ao permitir a terceirização sem quaisquer limites e garantias, a nova Lei agravará ainda mais a crise econômica e de arrecadação do Estado, pois, ao permitir a redução material de direitos e de benefícios mediante a diminuição significativa da renda do trabalhador, consentirá, de maneira proporcional, a redução da arrecadação de impostos. Além do mais, o projeto trará como consequência o aumento da sonegação fiscal e do não recolhimento de impostos, tendo em vista ser comum que as empresas terceirizadas, por não possuírem, em geral, uma razoável capacidade econômica, acabam por não honrar todos os compromissos fiscais, trabalhistas e previdenciários.

Para agravar o atual panorama do mundo do trabalho, o Congresso Nacional aprovou, no dia 11 de julho de 2017, de forma antidemocrática, a Reforma Trabalhista. A partir disso, perguntamos: o que a regulamentação da terceirização e a Reforma Trabalhista representam para o trabalho dos jovens no contexto de mudanças no mundo do trabalho?

Certamente essas medidas acarretarão o aumento da miséria social, caracterizada pela alta desigualdade social estimulada pelo aumento da concentração de renda. Avançará, sobretudo, a informalização do mercado de trabalho, o que representará a superexploração da força de trabalho, outra marca distintiva do capitalismo no Brasil. Nesse sentido, o processo de combate às desigualdades sociais deverá, de igual modo, arrefecer com as reduções e/ou extinções de programas sociais (Bolsa Família, Brasil Sem Miséria, Brasil Carinhoso etc.) de combate à pobreza absoluta ou à pobreza extrema.

\section{IMPLICAÇÕES NAS POLÍTICAS DE EDUCAÇÃO E TRABALHO PARA OS JOVENS NO BRASIL}

A partir de uma perspectiva articulada aos direitos à educação e ao trabalho, analisamos as políticas públicas e os instrumentos legais mais importantes concernentes à essas premissas constitucionais, observando a 
proteção legal integral e avaliando até que ponto esses direitos têm sido implementados no Brasil.

Em cada época, em menor ou maior grau de abrangência, podemos dizer que todas as Cartas Constitucionais elaboradas pelos legisladores brasileiros enfatizaram o tema "educação". A atual Constituição Federal (CF) enunciou o direito à educação como um direito social de todos e dever do Estado e da família, devendo ser promovida e incentivada com a colaboração da sociedade, visando ao pleno desenvolvimento da pessoa, seu preparo para o exercício da cidadania e sua qualificação para o trabalho (BRASIL, 1988).

Ao que parece, o Estado Brasileiro despertou, mesmo tardiamente, para a priorização do direito à educação. Vejamos o que preceitua o Art. 205, da CF:

A educação, direito de todos e dever do Estado e da família, será promovida e incentivada com a colaboração da sociedade, visando ao pleno desenvolvimento da pessoa, seu preparo para o exercício da cidadania e sua qualificação para o trabalho. (BRASIL, 1988).

A CF ainda estabelece alguns princípios através dos quais o direito à educação deverá ser pautada e, consequentemente, como o ensino deverá ser. São eles: a) igualdade de condições para o acesso e a permanência na escola; b) liberdade de aprender, de ensinar, de pesquisar e de divulgar o pensamento, a arte e o saber; c) pluralismo de ideias e de concepções pedagógicas e coexistência de instituições públicas e privadas de ensino; d) gratuidade do ensino público em estabelecimentos oficiais; e) valorização dos profissionais da educação escolar, garantidos, na forma da lei, planos de carreira. (BRASIL, 1998).

O Art. 227 da CF doutrina a proteção integral e a prioridade absolutas de políticas públicas eficazes na área da infância e das juventudes, concebendo como dever da família, da sociedade e do Estado, assegurar à criança e ao adolescente: o direito à vida, à saúde, à alimentação, à educação, ao lazer, à profissionalização, à cultura, à dignidade, ao respeito, à liberdade e à convivência familiar e comunitária, além de colocá-los a salvo de toda forma de negligência, de discriminação, de exploração, de violência, de crueldade e de opressão. (BRASIL, 1998).

Adite-se a esse pensamento, que o Art. 4ํㅜ, parágrafo único, alíneas "b", "c" e "d", da Lei n. ${ }^{\circ}$ 8.069/1990, criadora do Estatuto da Criança e do Adolescente (ECA), define que a garantia de prioridade absoluta cinge a precedência de atendimento nos serviços públicos ou de relevância pública. Pressupõe, ainda, a preferência na formulação e na execução de políticas 
sociais públicas a destinação privilegiada de recursos públicos nas áreas relacionadas com a proteção da infância e da juventude. (BRASIL, 1990).

No âmago das políticas públicas, o ECA trouxe propostas inovadoras, como a questão da profissionalização e da proteção no trabalho, pois contempla propostas que possibilitam a recriação de novas identidades para os jovens, até então sufocada e anulada pelas desigualdades sociais, além de resgatar o trabalho pela via da dignidade sem ferir os direitos à educação, ao lazer e à satisfação das necessidades básicas. Ou seja, traz a profissionalização e a proteção no trabalho como uma possibilidade, dentre muitas outras, para a emancipação do jovem.

No contexto da educação, o Brasil estatuiu a Lei n. ${ }^{\circ}$ 9.394/1996. Essa Lei estabelece dois níveis para a educação: Educação Básica e Educação Superior, contemplando, também, as denominadas modalidades de ensino, quais sejam: a Educação de Jovens e Adultos, a Educação Especial e uma modalidade complementar, a Educação Profissional. (BRASIL, 1996).

No plano infraconstitucional, a CLT consolidou a matéria em questão em seus Arts. 402 a 441 (BRASIL, 1943), reiteradas pela Carta Magna de 1988 quanto à idade mínima para o trabalho, citando, com inclusão, restrições a alguns tipos de trabalho e aludindo à modalidade de trabalho do menor aprendiz. Alude, de igual maneira, a atendimentos diferenciados para trabalhadores pais ou mães de crianças e de adolescentes. Assim, a regulamentação em comento passou por um processo de modernização com a promulgação das Leis $\mathbf{n}$. $^{10.097 / 2000,11.180 / 2005}$ e $11.788 / 2008$, as quais tiveram como objetivo incluir os jovens no mercado de trabalho, estimulando as empresas a oferecerem um programa de aprendizagem para jovens.

Cabe esclarecer que a aprendizagem, com fulcro nos Artigos 424 e 433 da CLT, é importante instrumento de profissionalização de adolescentes, visto que, além da formação geral, deve fornecer estudos de caráter técnico e a aquisição de conhecimentos e de aptidões práticas relativas ao exercício de determinadas profissões. Isso se daria na medida em que permitiria sua inserção simultânea no mercado de trabalho e em cursos de formação profissional, com garantia de direitos trabalhistas e previdenciários. (BRASIL, 1943).

De tal modo, a aprendizagem deve ser instituída em consonância com o princípio da proteção integral do adolescente, devendo ser respeitada a sua condição peculiar de pessoa em desenvolvimento e a capacitação profissional adequada ao mercado de trabalho. Sendo vedado, desse modo, o trabalho noturno, insalubre, perigoso ou prejudicial à sua formação psíquica, intelectual ou moral, de acordo com a norma constitucional.

Ademais, a Lei n. ${ }^{\circ} 12.852 / 2013$, que instituiu o Estatuto da Juventude, foi pensada como uma resposta do Legislativo às justas demandas dos jovens brasileiros, que agora dispõem de um instrumento legal diretamente 
voltado à proteção de seus direitos e ao fortalecimento de suas identidades e diversidades, individuais e coletivas. (BRASIL, 2013).

A CF, ao assegurar o direito à capacitação profissional, complementa o direito social genérico ao trabalho. Com o advento da Emenda Constitucional n. ${ }^{\circ} 65 / 2010$, o referido direito deixa de ser dirigido, exclusivamente, aos adolescentes, passando também a ser um direito dos jovens. Antes dessa alteração, o que mais se aproximava de uma garantia à formação profissional para os indivíduos que não fossem adolescentes era o direito à educação com o objetivo da qualificação para o trabalho, com fulcro no Art. 205 da CF.

A Carta Magna também prevê a qualificação para o trabalho como uma das finalidades da educação brasileira, estando descriminada na Lei de Diretrizes e Bases na Educação Nacional (LDBN - n. ${ }^{\circ}$ 9.394/1996). No Art. 1ำ fica elucidado que a educação abrange os processos formativos que se desenvolvem na família, na convivência humana, no trabalho, nas escolas, nos movimentos sociais, nas organizações da sociedade civil e nas manifestações culturais, de maneira a objetivar a educação escolar vinculando-a ao mundo do trabalho e à prática escolar. (BRASIL, 1996).

Enfatizamos, pois, que a formação profissional e a formação no trabalho do jovem estão no centro da atual crise brasileira, tendo em vista o processo de inclusão ou exclusão dos bens e serviços prestados pelo Estado a esse estrato da população. Crise que envolve questões políticas, econômicas, trabalhistas, culturais e sociais incrustradas em um Estado que tem, desde as últimas décadas do Século XX, se caracterizado como liberal, embora, apresente, em alguns momentos, mesclas de um projeto societário que em disputa não tem satisfeito à classe trabalhadora por não garantir seus direitos fundamentais.

A Lei n. ${ }^{\circ}$ 12.852/2013 promulgou 0 Estatuto da Juventude, determinando quais são os direitos dos jovens que devem ser garantidos e promovidos pelo Estado brasileiro, independentemente de quem esteja à frente da gestão dos poderes públicos. O referido Estatuto estabelece, ainda, dentre as garantias já previstas pela Constituição, quais são as especificidades da juventude que precisam ser afirmadas. Configura-se, desse modo, como instrumento que legitima essa parcela da população como sujeitos de direitos. (BRASIL, 2013).

O Estatuto ressalta a importância das políticas afirmativas e da expansão da educação superior nas instituições públicas, do financiamento e da assistência estudantil, das bolsas de estudos e do transporte escolar. Também são destacadas as necessidades dos jovens negros, do campo, dos indígenas e daqueles com deficiência. É garantida a liberdade de organização dos estudantes e a sua participação efetiva para a gestão democrática das escolas e das universidades.

Com fulcro no regulamento, é garantido, também, que todo jovem possa ter acesso à profissionalização, ao trabalho e à renda, em condições 
de liberdade, equidade e segurança, além de remuneração adequada e com proteção social. Prevê a promoção de formas coletivas de organização para o trabalho, de redes de economia solidária e da livre associação. Dada as condições especiais, antevê a compatibilização entre horários de trabalho e de estudo.

Em especial, no que tangencia o direito à educação, entendemos que os preceitos legais caminharam no sentido de promover o direito do jovem à educação em todos os seus níveis e modalidades, bem como o reconhecimento da diversidade das juventudes nas políticas de acesso, de assistência estudantil e, certamente, da participação democrática nas instâncias educacionais.

O Estatuto robustece a importância do trabalho decente para as juventudes, exercido em condições e com remuneração e proteção social adequados, e de ações de geração de emprego, de economia solidária, de cooperativismo e de desenvolvimento sustentável.

O texto constitucional também relaciona profissionalização e educação com o desenvolvimento da pessoa em sua integralidade e potencialidades. $O$ objetivo da profissionalização é, portanto, educacional, posto que além da sua especificidade, soma-se a ela outros valores que se sobrepõem ao mundo da educação pelo trabalho.

Ainda em referência à Educação Profissional ou ao preparo para o trabalho, a LDB entende que a função da escola é a de preparar os alunos com conhecimentos básicos sobre as profissões e sobre as perspectivas para o ingresso no mercado de trabalho. Tem-se, ainda, a concepção de que deverá ocorrer a preparação para o exercício da cidadania, da autonomia e do pensamento de forma ética.

Contudo, os problemas da política de formação e qualificação profissional começaram por seus objetivos, especialmente daqueles concernentes à relação entre escola e mundo do trabalho. Consoante a esse argumento, é importante ressaltar que a LDB não promove a integração entre escola e mundo do trabalho, já que se restringe à formação de jovens e de adultos para a atividades produtivas demandadas pelo mercado.

O mundo do trabalho vem sofrendo os reflexos dessas contradições do sistema educacional e, mais acentuadamente, os adolescentes e os jovens que estão à procura de emprego. Ressaltamos que, em um país capitalista, a ideia é a de atender ao sistema, e isso significa que os trabalhadores devem adequar-se prioritariamente às necessidades do mercado, atendendo à lógica produtiva e acumulativa do capital, baseada na exploração da força de trabalho.

Percebemos que, no mundo capitalista brasileiro, a educação é articulada ao trabalho e desenvolvida a partir da proposta de que o indivíduo tem de se enquadrar nas exigências do mercado de trabalho. Isso tem gerado 
mudanças e desafios, posto que a detenção do conhecimento e o acesso à informação, de maneira mais rápida e eficiente, é o diferencial para os indivíduos terem acesso ao mercado de trabalho, mas esse não tem vagas para todos.

Em decorrência dessa cruel realidade, estabeleceu-se um novo perfil para o trabalhador, alicerçado no "pensar" e não mais apenas no "fazer". A educação passou a ser condicionada com base nas competências, na empregabilidade, na qualificação e na especialização. Verificamos que o discurso da empregabilidade, fundamentado no profissional polivalente, capacitado e qualificado para as novas exigências do mercado de trabalho passa a ser a nova retórica das instituições educacionais, as quais contribuem e promovem a "transformação" do trabalhador dentro dos parâmetros capitalistas.

Agora, voltemos às questões: o que as políticas de educação e de trabalho, acopladas à terceirização, significam para jovens inseridos em uma concepção histórico-dialética das atividades humanas? Quais as condições de trabalho e as perspectivas educacionais para jovens com as atuais políticas direcionadas à terceirização?

As transformações pelas quais vêm passando o mundo do trabalho, a economia mundial e a brasileira nos últimos anos são, de maneira geral, desfavoráveis à evolução do emprego e da força de trabalho e, nesse cenário, a população juvenil é a mais prejudicada, haja vista a menor experiência apresentada por esta no momento da busca por emprego.

Segundo o Instituto Brasileiro de Geografa e Estatística (IBGE), os últimos anos têm sido marcados pela ampliação da taxa de desemprego e de inatividade entre a população juvenil. Assim, a inserção destes em segmentos de baixa produtividade e maior precariedade das condições de trabalho tem se ampliado.

É importante ressaltar que, nesse contexto, os jovens com situações socioeconômicas menos privilegiadas são os mais atingidos. Frise-se, ainda, que os jovens cujas famílias têm menor poder aquisitivo encontram mais dificuldades para se inserirem no mercado de trabalho. E a não inserção desses jovens resulta em maior desemprego para esse amplo segmento populacional, proporcionando, desse modo, a retroalimentação da pobreza.

O baixo crescimento da atividade econômica nos últimos anos limitou bastante a geração de novos empregos, prejudicando a todos os trabalhadores. Entretanto, para os jovens, essas dificuldades de inserção se inscrevem ainda maiores, pois estes apresentam menor experiência no momento da disputa pelo posto de trabalho.

Esses jovens vivem o seguinte dilema: precisam de experiência para conseguir um trabalho ao mesmo tempo que precisam trabalhar para conseguir experiência. Esse paradoxo contribui para a precarização das 
relações de trabalho e os impelem aos subempregos para, pelo menos, manterem um certo status de trabalhador e minimizarem os sentimentos de incapacidade e de inutilidade para si mesmos e para a sociedade.

Salazar (2009) afirma que devido ao desemprego e à precarização do trabalho, determinados segmentos, em particular os jovens e os velhos, deixam de ter lugar na sociedade, sendo classificados como trabalhadores excedentes, sem qualificação e inúteis.

Para Camarano (2006), as políticas públicas educacionais ainda são deficientes em promover a universalização do ensino. Essa autora ainda enfatiza que a desigualdade educacional se reflete nas desigualdades sociais. Assim, os jovens que possuem condições socioeconômicas mais favoráveis investem em mais anos de estudo, retardando a entrada no mercado de trabalho, porém, com perspectiva de uma melhor inserção no futuro. Já os menos favorecidos economicamente precisam conciliar os estudos com o trabalho, abandonando, na maioria das vezes, os estudos, já que necessitam de renda para sobreviverem.

Freitas e Papa (2003) sinalizam que os jovens mais pobres não acreditam na escola como garantia de empregabilidade, visto que, mesmo os que conseguem terminar o Ensino Médio, acabam esbarrando em processos de seleção com candidatos que já possuem curso universitário.

Dessa forma, observamos que as políticas públicas voltadas para a população jovem no Brasil ainda não possuem o caráter universal. Ao contrário, estão enfocadas nos jovens pobres e atuam, em geral, como instrumentos de prevenção da criminalidade, mostrando-se deficitárias, pois não contribuem significativamente com a caminhada desses jovens na direção de um futuro garantidor de direitos sociais e, por consequência, da realização da dignidade da pessoa humana.

\section{CONSIDERAÇÕES FINAIS}

Diante deste estudo, podemos concluir que não é de agora que o mundo do trabalho sofre com o processo dinâmico de reestruturação produtiva continuamente realizada pelo capitalismo em sua busca incessante acumulação de capital. Desse modo, o que estamos assistindo, agora, nada mais é do que uma nova etapa desse processo, marcada por mais uma crise econômica, cujos efeitos têm sido altamente nocivos para as classes trabalhadoras.

Vimos que, certamente, a classe mais lesada nesse cenário é a das juventudes, pois além das mudanças no mundo do trabalho, a falta de políticas públicas educacionais eficientes e eficazes, a terceirização, a precarização, e a mais recente Reforma Trabalhista (Lei n. ${ }^{\circ} 13.467$, de 13 de 
julho de 2017), no geral, configurada pela nova ordem neoliberal globalizante, tem provocado uma contínua desvalorização do trabalho, fazendo crescer a preocupação com 0 aumento do desemprego, da pobreza e com 0 achatamento salarial, tendo em vista que as condições de trabalho se deterioraram com o incremento da carga horária laboral, a submissão a atividades exaustivas, o crescimento do trabalho eventual e informal, entre outras precariedades que pouco tem a ver com a educação.

A participação precoce do adolescente no mercado de trabalho tem provocado muitos questionamentos, dificultando e interferindo na implementação de políticas específicas voltadas para o trabalho do jovem. Sem ressaltar que as políticas públicas educacionais não possuem uma centralidade quando o assunto é educação, servindo-se, muitas vezes, às práticas imediatistas e assistencialistas que não combatem de forma mais incisiva as vulnerabilidades que os jovens passam como a dificuldade de acesso à educação e ao trabalho.

Por fim, diante desse cenário de crise, entendemos que a nova lei da terceirização, liberada para quaisquer das atividades das empresas e do Estado, incrementará os índices de desemprego no Brasil. Além do mais, possibilitará a redução material de direitos dos trabalhadores brasileiros, dentre eles remuneração e benefícios, e, sobretudo, aumentará os índices de acidentes de trabalho, inclusive os fatais, bem como os de doenças ocupacionais no Brasil, o que representará imenso retrocesso social para nosso país, expandindo a desigualdade social presente na sociedade brasileira há séculos.

\section{REFERÊNCIAS}

ANTUNES, R. Os Sentidos do Trabalho: ensaio sobre a afirmação e a negação do trabalho. 7. ed. São Paulo: BOITEMPO, 2005.

ALVES, G. $O$ novo (e precário) mundo do trabalho: reestruturação produtiva e crise do sindicalismo. São Paulo: BOITEMPO, 2005.

sociologia do trabalho. Bauru, Editora Praxis, 2007.

BRASIL. Constituição da República Federativa do Brasil de 1988. Disponível

em:<http://www.planalto.gov.br/ccivil_03/Constituicao/Constituiçao.htm>. Acesso em 09 de fevereiro de 2018.

Consolidação das Leis do Trabalho. Disponível em:<http://www.planalto.gov.br/ccivil_03/Decreto-Lei/Del5452.htm>. Acesso em 09 de fevereiro de 2018. 
Diretrizes e Bases da Educação Nacional. Disponível em:<http://www.planalto.gov.br/ccivil_03/leis/L9394.htm>. Acesso em 12 de julho de 2017.

Estatuto da Criança e do Adolescente. Disponível em: <http://www.planalto.gov.br/ccivil_03/Leis/L8069.htm>. Acesso em 12 de julho de 2017.

Lei $\mathrm{n} . \mathbf{0}$ 13.429, de 31 de março de 2017. Altera dispositivos da Lei oㅜ 6.019, de 3 de janeiro de 1974, que dispõe sobre o trabalho temporário nas empresas urbanas e dá outras providências; e dispõe sobre as relações de trabalho na empresa de prestação de serviços a terceiros. Disponível em: <http://www.planalto.gov.br/ccivil_03/_ato2015-2018/2017/lei/L13429.htm>. Acesso em 05 de janeiro de 2018.

Lei n.o 13.467, de 13 de julho de 2017. Altera a Consolidação das Leis do Trabalho (CLT), aprovada pelo Decreto-Lei $n^{\circ} 5.452$, de $1^{\circ}$ de maio de 1943, e as Leis $\mathrm{n}^{\mathrm{os}} 6.019$, de 3 de janeiro de 1974, 8.036, de 11 de maio de 1990, e 8.212, de 24 de julho de 1991, a fim de adequar a legislação às novas relações de trabalho. Disponível em: <http://www.planalto.gov.br/ccivil_03/_ato2015-2018/2017/lei/13467.htm>. Acesso em 05 de janeiro de $201 \overline{.}$.

(TST). Súmula n.- 331 . Súmulas do Tribunal Superior do Trabalho <http://www3.tst.jus.br/jurisprudencia/Sumulas_com_indice/Sumulas_Ind_301 350.html >. Acesso em 05 de janeiro de 2018.

CAMARANO, A. A. (2006). Transição para a vida adulta ou vida adulta em transição. Rio de Janeiro: IPEA.

FREITAS, M. V., e PARA, F. C. (2003). Políticas Públicas: Juventude em Pauta. São Paulo: Cortez. Ação Educação Assessoria, Pesquisa e Informação: Fundação Friedrich Ebert.

FRIGOTTO, Gaudêncio. Juventude, Trabalho e Educação no Brasil: perplexidades, desafios e perspectivas. In: NOVAES, Regina e VANUCHI, Paulo. Juventude e sociedade: trabalho, educação, cultura e participação. São Paulo: Fundação Perseu Abramo, 2004.

HARVEY, D.. A condição pós-moderna. São Paulo: Loyola, 1993.

MARK, K. Trabalho assalariado e capital \& salário, preço e lucro. 2. ed. São Paulo: Expressão popular, 2010.

PETRIN, N. Terceirização. Estudo prático. Disponível em: $<$ https://www.estudopratico.com.br/terceirizacao/>. Acesso em 10 de janeiro de 2018.

SALAZAR, S. N. (2009). A centralidade da categoria trabalho na contemporaneidade. Revista em debate, Revista eletrônica do departamento de serviço social. Disponível em: $<$ http://www.maxwell.lambda.ele.pucrio.br/rev_emdebate.php?strSecao=input0 $>7$. Acesso em 10 de janeiro de 2018. 